\title{
Influence on ocular surface after cataract surgery and effect of topical diquafosol on postoperative dry eye: a multicenter prospective randomized study
}

\author{
This article was published in the following Dove Press journal: \\ Clinical Ophthalmology \\ 17 March 2017 \\ Number of times this article has been viewed
}

\section{Kensaku Miyake' \\ Norihiko Yokoi ${ }^{2}$ \\ On behalf of Dry Eye \\ After Cataract Surgery \\ Investigational Study Group \\ (DASIS group)}

'Miyake Eye Hospital, Nagoya, 2Department of Ophthalmology, Kyoto Prefectural University of Medicine, Kyoto, Japan
Correspondence: Kensaku Miyake Shohzankai Medical Foundation, Miyake Eye Hospital, 3-14-20, Ozone, Kita-Ku, Nagoya 462-0825, Japan

$\mathrm{Tel}+8|529| 58001$

Fax +8I 529158525

Email miyake@spice.or.jp
Purpose: To investigate influences of 3\% diquafosol sodium ophthalmic solution (DQS) on ocular surface after cataract surgery and effects on postoperative dry eye.

Design: This study had two consecutive prospective study phases. The former was an observational study from before cataract surgery to 4 weeks after surgery and the latter was a randomized open-label study from 4 to 8 weeks after surgery.

Methods: Subjects were 433 eyes of 433 patients undergoing cataract surgery with intraocular lens implantation. Dry eye examination of tear breakup time (BUT), corneal and conjunctival fluorescein staining scores, total subjective symptom score (12 symptoms), and Schirmer I test were conducted before surgery and 4 weeks after surgery. Patient demographics and these examination results were used to analyze risk factors to predict postoperative dry eye. In a randomized study, 154 eyes diagnosed with dry eye postoperatively were applied either DQS or artificial tears (AT) six times daily for 4 weeks. The data of the examinations were compared.

Results: At 4 weeks after surgery, BUT was shortened significantly $(P=0.036)$, fluorescein staining score increased significantly $(P=0.012)$, but total subjective symptom score was significantly improved $(P<0.001)$. The majority of postoperative dry eye was shortened BUT type $(53.1 \%)$. The dry eye prevalence after surgery decreased $(55.7 \%)$ compared with before surgery $(69.7 \%)$. Females and the patient with dry eye symptoms before surgery had significant risk factors for postoperative dry eye. In a randomized study, BUT was significantly prolonged in the DQS group $(P=0.015)$, but not in the AT group. Fluorescein staining score was significantly improved in both groups $(P<0.001)$. Total subjective symptom score was significantly decreased in the AT group $(P<0.001)$, but not in the DQS group.

Conclusion: Our study suggests that cataract surgery has harmful effects on tear film stability and ocular surface, and DQS has a capability to improve them.

Keywords: cataract surgery, dry eye, unstable tear film, tear break up time, diquafosol ophthalmic solution

\section{Introduction}

Cataract surgery with intraocular lens (IOL) implantation is safe and produces stabilized postoperative outcomes. However, challenges remain to achieve more comfortable eyes with a higher quality of vision. Factors that contribute to such improvements are optics of the IOLs, ${ }^{1}$ including the so-called premium IOLs, corneal configuration, ${ }^{2}$ and tear film condition. ${ }^{3,4}$ 
Perioperative abnormalities of the tear film are recently being noted as perioperative dry eye. The International Dry Eye Workshop in 2007 stated that

Dry eye is a multifactorial disease of the tears and ocular surface that results in symptoms such as ocular discomfort, visual disturbance, and tear film instability with potential damage to the ocular surface. ${ }^{3}$

Risk factors for perioperative dry eye have been reported to include forceful opening of the eye lids, ${ }^{5}$ aging, ${ }^{6,7}$ light and heat from the operating microscope, ${ }^{8,9}$ preservatives in eye drops,${ }^{10}$ topical nonsteroidal anti-inflammatory drugs (NSAIDs), ${ }^{11}$ topical anesthetics, ${ }^{12,13}$ and cleansing of the conjunctival sac and lids with povidone iodine. ${ }^{14}$ The mechanism, through which these risk factors induce dry eye after cataract surgery with IOL implantation, its incidence, as well as its prevention and treatment method have not yet been established. ${ }^{15-22}$

However, pathophysiology and concept of the treatment of general dry eye are recently becoming more apparent. ${ }^{3,23,24}$ The concept is that risk factors of dry eye induce abnormality of the tear film or of the corneal and conjunctival epithelium, or of both, leading to ocular discomfort or visual functional disturbance. The tear film covers the epithelium to protect its functions, such as barrier via the avoidance from desiccation. The function of the tear film and corneal and conjunctival epithelium complements each other; and therefore, damage to either the tear film or the epithelium results in a vicious cycle, which may ultimately result in dry eye syndrome.

On the basis of the recent understanding of dry eye pathophysiology, there has been a shift in treatment from simply lubricating the ocular surface using artificial tears (AT) or sodium hyaluronate to applying medications to secretion of water and mucin. Diquafosol sodium, a relatively new medication, is a dinucleotide derivative and a purinoceptor agonist. It acts on the $\mathrm{P} 2 \mathrm{Y}_{2}$ receptor on the ocular surface to increase the concentration of intercellular calcium ions leading to the secretion of aqueous tears and mucin. ${ }^{25-30}$ Animal studies ${ }^{27-29,31}$ revealed diquafosol sodium to act on conjunctival epithelium and goblet cells of the epithelium, inducing secretion of aqueous fluid and mucin, protecting the corneal epithelium from desiccation, and improving barrier function of the corneal epithelium via the enhancement of tear film stability. Recent studies on humans also have reported that 3\% diquafosol sodium ophthalmic solution (DQS) has been found to be effective on general dry eye syndrome. ${ }^{32-34}$ However, the effect of DQS on dry eye after cataract surgery was scarce ${ }^{21,22}$ and no prospective multicenter study has been conducted for this.
In the current multicenter prospective study, we first investigated the influence on ocular surface after the cataract surgery with IOL implantation by the dry eye examination. Furthermore, we then carried out a randomized comparative analysis to confirm the effects of DQS and AT on the patients diagnosed dry eye 4 weeks post operation.

\section{Materials and methods Study design}

This study was carried out at 12 eye centers in Japan. It had two consecutive study phases. The former was an observational study from before cataract surgery to 4 weeks after surgery and the latter was a prospective randomized open-label parallel group comparison study from 4 weeks after surgery to 8 weeks after surgery with DQS (DIQUAS, Santen Pharmaceutical, Osaka, Japan) or AT (MYTEAR, Senju Pharmaceutical, Osaka, Japan). All patients were given full explanation of this study, and a written informed consent was obtained from all subjects. This study followed the tenets of the Declaration of Helsinki, and it was approved by the Institutional Review Board and the Ethics Committee of Kimura Hospital (Tokyo). A registration of this study was done at http://www.umin.ac.jp/ (Identification No UMIN000016060).

\section{Subjects for the observational study}

Patients subjected to an age-related cataract surgery using phacoemulsification (PEA) were enrolled in the first observational study. Patients were excluded if they had allergic conjunctivitis, diabetic retinopathy, necessity of topical ocular medications for glaucoma or uveitis, or necessity of contact lenses during this study phase. Also, patients were excluded if they had a history of laser-assisted in situ keratomileusis, palpebral surgery, corneal transplantation, allogeneic hematopoietic stem cell transplantation, medication with eye drops for dry eye within 2 weeks of this study examination before surgery, or medication with a device for dry eye (eg, punctal plug). After incision and PEA to treat the cataract, a foldable acrylic posterior chamber IOL was implanted in the capsular bag. With patients undergoing bilateral surgery, the eye having undergone surgery first was enrolled to the study. Postoperative topical medications with steroid, antibacterial drug, and NSAIDs were integrated in particular brands as much as possible. The steroid eye drops such as fluorometholone $0.1 \%$ (FLUMETHOLON, Santen Pharmaceutical, Osaka, Japan) and antibacterial drug such as levofloxacin 1.5\% (CRAVIT; Santen Pharmaceutical, Osaka, Japan) were instilled for 4 weeks after surgery. Also, NSAIDs such as diclofenac 
sodium $0.1 \%$ (DICLOD; Wakamoto Pharmaceutical, Tokyo, Japan) was instilled for 8 weeks after surgery.

\section{Clinical data collection, dry eye diagnostic, and dry eye type classification}

Dry eye examination through tear breakup time (BUT) using a fluorescein, corneal, and conjunctival fluorescein staining score, a subjective symptom questionnaire, and Schirmer I test were evaluated before and 4 weeks after cataract surgery. BUT was evaluated three times through its mean value. Corneal and conjunctival fluorescein staining scores were evaluated in three areas (the temporal bulbar conjunctiva, nasal bulbar conjunctiva, and cornea), scored on a 0 - to 3-point scale (0: no damage to 3: damage in the entire area) and then totaled (maximum $=9$ points). The subjective symptom was evaluated with an interview form including a frequency of 12 dry eye symptoms as eye fatigue, eye pain, eye discharge, foreign body sensation, tearing, blurred vision, itchy eye, heaviness, red eye, eye discomfort, dryness, and photophobia. ${ }^{35}$ This questionnaire is generally used for the evaluation of dry eye in Japan. It was quantified as follows: score $0=$ never, score $1=$ rarely, score $2=$ sometimes, and score $3=$ all of the time. The patient replied that there was at least one symptom, such as "sometimes" (score 2) or "all of the time" (score 3), that was considered to be positive.

Dry eye was diagnosed based on the Japanese diagnostic criteria. ${ }^{23}$ Definite dry eye was determined to have positive subjective symptoms ( $\geq$ score 2 ) and tear film abnormalities (BUT $\leq 5 \mathrm{~s}$ or Schirmer I test $\leq 5 \mathrm{~mm}$ ) and a positive fluorescein staining score ( $\geq$ score 3 ). Probable dry eye was determined to have two symptoms out of three (positive subjective symptom, tear film abnormality, and positive fluorescein staining). To consider the adverse effects of cataract surgery on dry eye, we analyzed the change of dry eye diagnostic classification. A definite dry eye patient at 4 weeks after surgery changed from probable at pre-surgery examination and was determined to have worsened dry eye. The probable or definite dry eye patient at 4 weeks after surgery changed from non-dry eye at pre-surgery examination and was determined to have developed dry eye.

To analyze the ratio according to dry eye types, we divided dry eye patients into two types. One type was unstable tear film dry eye called short BUT type dry eye (Schirmer I test $>5 \mathrm{~mm}$, BUT $\leq 5 \mathrm{~s}$ and positive subjective symptoms). This type has a normal tear volume. The other was tear-deficient dry eye (Schirmer I test $\leq 5 \mathrm{~mm}$ and positive subjective symptoms).

\section{Risk analysis for dry eye after cataract surgery}

We performed a risk analysis for developing dry eye after cataract surgery. In this analysis, we examined the influence of patient demographics and the result of dry eye examination before and after cataract surgery.

\section{Prospective randomized study with DQS or AT}

At the examination 4 weeks after surgery, the patient with definite dry eye or probable dry eye except no fluorescein staining score (score 0 ) was enrolled in the prospective randomized study. The qualified patients were randomized into one of the two groups, one group with DQS and the other with AT. Randomization was performed 1:1 using the permuted block method and the envelope method. Patients received either DQS or AT six times a day for 4 weeks and were given dry eye examinations before and 4 weeks after the treatment. The dry eye examination was conducted in the same manner as the observational study.

\section{Statistical analysis}

One-sample $t$-test and the Wilcoxon rank-sum test were used to analyze the results of dry eye examinations before and 4 weeks after cataract surgery. For the risk analysis, univariate logistic regression analysis was used. For the analysis for the effect of DQS/AT after cataract surgery, Fisher's exact test, $t$-test, and the Wilcoxon rank-sum test were used to analyze the background. $T$-test and the Wilcoxon rank-sum test were used to analyze the result of the dry eye examination. All statistical analyses were performed using SAS version 9.4 (SAS Institute INC, Cary, NC, USA) by Medical TOUKEI Corporation (Tokyo, Japan). $P$-values $<0.05$ were considered significant.

\section{Results \\ Subject demographics of the observational study}

A total of 433 eyes of 433 patients (males: 199, females: 234 , average age: $71.9 \pm 7.5$ years) subjected to age-related cataract surgery were enrolled in the observational study. Table 1 shows the demographics of 433 patients.

\section{Change in signs and symptoms before and 4 weeks after surgery}

Table 2 shows the change in BUT, corneal and conjunctival fluorescein staining scores, Schirmer I test, and the total score 
Table I Demographics of the observational study subjects

\begin{tabular}{ll}
\hline Background factors & Total (\%) \\
\hline $\begin{array}{l}\text { Number of patients analyzed } \\
\text { Sex }\end{array}$ & $433(100.0)$ \\
$\quad$ Male & $199(46.0)$ \\
$\quad$ Female & $234(54.0)$ \\
Age (year), mean \pm SD & $71.9 \pm 7.5$ \\
Site of incision & \\
$\quad$ Cornea & $159(36.7)$ \\
Sclerocornea & $102(23.6)$ \\
$\quad$ Transconjunctival sclerocornea & $172(39.7)$ \\
Width of incision, mm (phacoemulsification), mean \pm SD & $2.32 \pm 0.14$ \\
Anesthetic procedure & \\
$\quad$ With eye drops & $413(95.4)$ \\
With retrobulbar injection & $2(0.5)$ \\
$\quad$ With tenon injection & $18(4.2)$ \\
Surgical time, minutes, mean \pm SD & $8.6 \pm 3.4$ \\
\hline
\end{tabular}

Abbreviation: SD, standard deviation.

Table 2 Change of signs and symptoms according to the category of dry eye diagnosis

\begin{tabular}{|c|c|c|c|}
\hline \multirow{2}{*}{$\begin{array}{l}\text { Category of dry eye } \\
\text { diagnosis before } \\
\text { surgery }\end{array}$} & \multicolumn{2}{|c|}{ Examination point } & \multirow{2}{*}{$\begin{array}{l}\text { Comparison } \\
\text { within-group, } \\
P \text {-value }\end{array}$} \\
\hline & $\begin{array}{l}\text { Before } \\
\text { surgery }\end{array}$ & $\begin{array}{l}4 \text { weeks } \\
\text { after surgery }\end{array}$ & \\
\hline \multicolumn{4}{|c|}{ Tear breakup time (seconds) } \\
\hline Total & & & $0.036^{\mathrm{a}, *}$ \\
\hline Mean \pm SD & $4.75 \pm 2.63$ & $4.50 \pm 2.67$ & \\
\hline Number of patients & 433 & 433 & \\
\hline Non-dry eye & & & $<0.00$ I $^{\mathrm{a}, * *}$ \\
\hline Mean \pm SD & $7.02 \pm 2.62$ & $5.74 \pm 2.95$ & \\
\hline Number of patients & $|3|$ & $|3|$ & \\
\hline Probable & & & $0.269^{\mathrm{a}}$ \\
\hline Mean \pm SD & $3.96 \pm 2.10$ & $4 .|4 \pm 2.4|$ & \\
\hline Number of patients & 217 & 217 & \\
\hline Definite & & & $0.169^{a}$ \\
\hline Mean \pm SD & $3.24 \pm 1.32$ & $3.53 \pm 2.13$ & \\
\hline Number of patients & 85 & 85 & \\
\hline Probable + definite & & & $0.105^{\mathrm{a}}$ \\
\hline Mean \pm SD & $3.76 \pm 1.94$ & $3.96 \pm 2.35$ & \\
\hline Number of patients & 302 & 302 & \\
\hline \multicolumn{4}{|c|}{ Corneal and conjunctival fluorescein staining scores } \\
\hline Total & & & $0.012^{\mathrm{a}, *}$ \\
\hline Mean \pm SD & $1.5 \pm 1.4$ & $1.6 \pm 1.3$ & \\
\hline Number of patients & 433 & 433 & \\
\hline Non-dry eye & & & $<\left.0.00\right|^{\mathrm{a}, * *}$ \\
\hline Mean \pm SD & $0.7 \pm 0.8$ & $1.2 \pm 1.2$ & \\
\hline Number of patients & $|3|$ & $|3|$ & \\
\hline Probable & & & $<0.00$ I $^{\mathrm{a}, * *}$ \\
\hline Mean \pm SD & $1.1 \pm 1.0$ & $1.5 \pm 1.2$ & \\
\hline Number of patients & 217 & 217 & \\
\hline Definite & & & $<0.00$ I $^{\mathrm{a}, * *}$ \\
\hline Mean \pm SD & $3.5 \pm 1.0$ & $2.6 \pm 1.2$ & \\
\hline Number of patients & 85 & 85 & \\
\hline Probable + definite & & & $0.720^{\mathrm{a}}$ \\
\hline Mean \pm SD & $1.8 \pm 1.5$ & $1.8 \pm 1.3$ & \\
\hline Number of patients & 302 & 302 & \\
\hline
\end{tabular}

(Continued)
Table 2 (Continued)

\begin{tabular}{|c|c|c|c|}
\hline \multirow{2}{*}{$\begin{array}{l}\text { Category of dry eye } \\
\text { diagnosis before } \\
\text { surgery }\end{array}$} & \multicolumn{2}{|c|}{ Examination point } & \multirow{2}{*}{$\begin{array}{l}\text { Comparison } \\
\text { within-group, } \\
P \text {-value }\end{array}$} \\
\hline & $\begin{array}{l}\text { Before } \\
\text { surgery }\end{array}$ & $\begin{array}{l}4 \text { weeks } \\
\text { after surgery }\end{array}$ & \\
\hline \multicolumn{4}{|l|}{ Schirmer I test } \\
\hline Total & & & $0.209^{a}$ \\
\hline Mean \pm SD & $11.8 \pm 9.0$ & $12.3 \pm 9.9$ & \\
\hline Number of patients & 433 & 433 & \\
\hline Non-dry eye & & & $0.205^{\mathrm{a}}$ \\
\hline Mean \pm SD & $14.7 \pm 9.4$ & $15.7 \pm 10.5$ & \\
\hline Number of patients & $|3|$ & $|3|$ & \\
\hline Probable & & & $0.252^{\mathrm{a}}$ \\
\hline Mean \pm SD & $10.5 \pm 8.9$ & $11.2 \pm 9.3$ & \\
\hline Number of patients & 217 & 217 & \\
\hline Definite & & & $0.388^{a}$ \\
\hline Mean \pm SD & $10.4 \pm 7.6$ & $9.8 \pm 8.8$ & \\
\hline Number of patients & 85 & 85 & \\
\hline Probable + definite & & & $0.534^{\mathrm{a}}$ \\
\hline Mean \pm SD & $10.5 \pm 8.5$ & $10.8 \pm 9.2$ & \\
\hline Number of patients & 302 & 302 & \\
\hline \multicolumn{4}{|c|}{ Total score of 12 subjective symptoms } \\
\hline Total & & & $<0.00 \mathrm{I}^{\mathrm{b}, * *}$ \\
\hline Mean \pm SD & $8.8 \pm 5.5$ & $4.5 \pm 4.6$ & \\
\hline Number of patients & 431 & 431 & \\
\hline Non-dry eye & & & $<0.00 \mathrm{I}^{\mathrm{b}, * *}$ \\
\hline Mean \pm SD & $6.8 \pm 5.4$ & $3.6 \pm 4.2$ & \\
\hline Number of patients & $|3|$ & 130 & \\
\hline Probable & & & $<0.00 \mathrm{I}^{\mathrm{b}, * *}$ \\
\hline Mean \pm SD & $9.2 \pm 5.1$ & $4.5 \pm 4.4$ & \\
\hline Number of patients & 216 & 216 & \\
\hline Definite & & & $<0.00 \mathrm{I}^{\mathrm{b}, * *}$ \\
\hline Mean \pm SD & $\mid I .1 \pm 5.6$ & $5.8 \pm 5.2$ & \\
\hline Number of patients & 84 & 85 & \\
\hline Probable + definite & & & $<0.00 \mathrm{I}^{\mathrm{b}, * *}$ \\
\hline Mean \pm SD & $9.7 \pm 5.3$ & $4.9 \pm 4.7$ & \\
\hline Number of patients & 300 & 301 & \\
\hline
\end{tabular}

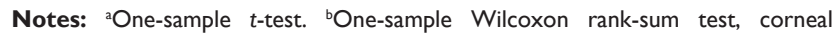
and conjunctival fluorescein staining scores were evaluated in three areas (the temporal bulbar conjunctiva, nasal bulbar conjunctiva, and cornea), scored on a 0 - to 3-point scale (0: no damage to 3: damage in the entire area) and then totaled (maximum $=9$ points). Subjective symptom score; score $0=$ never, score $\mathrm{I}=$ rarely, score $2=$ sometimes, score $3=$ all of the time. $* P<0.05 ; * * P<0.001$.

Abbreviation: SD, standard deviation.

of 12 subjective symptoms before and 4 weeks after surgery according to the classification of the dry eye diagnosis.

BUT 4 weeks after surgery was significantly shorter than before $(P=0.036)$. In non-dry eye subjects at before surgery, BUT became significantly shorter too $(P<0.001)$. However, in definite or probable dry eye patients before surgery, there was no significant difference of BUT between pre- and postcataract surgery. In patients with developed dry eye, BUT became significantly shorter 4 weeks after surgery (before: $6.44 \pm 2.73 \mathrm{~s}$, after: $3.99 \pm 2.56 \mathrm{~s}, \mathrm{n}=41, P<0.001, T$-tests). Also, in non-dry eye subjects through the surgery, BUT became significantly shorter too (before: $7.28 \pm 2.54 \mathrm{~s}$, after: $6.54 \pm 2.78 \mathrm{~s}, \mathrm{n}=90, P=0.004, T$-tests). 
The fluorescein staining score 4 weeks after surgery was significantly higher than before surgery $(P=0.012)$. Also, in non-dry eye subjects at before surgery, it became significantly higher too $(P<0.001)$. And, in probable dry eye at before surgery, it was significantly higher too $(P<0.001)$. On the other hand, in patients with definite dry eye before surgery, the fluorescein staining score after surgery decreased significantly $(P<0.001)$. The fluorescein staining score 4 weeks after surgery became significantly higher in developed dry eye (before surgery: $1.0 \pm 0.9$ score, after surgery: $2.3 \pm 1.3$ score, $\mathrm{n}=41, P<0.001, T$-tests).

The total score of 12 subjective symptoms 4 weeks after surgery was significantly decreased than before $(P<0.001)$. Each subgroup (non-dry eye, definite, probable dry eye before surgery) showed in the same manner significantly $(P<0.001)$. About individual subjective symptoms of total patients, blurred vision, photophobia, eye fatigue, eye discharge, tearing, itchy eye, heaviness, red eye, and ocular discomfort especially showed significant improvement as $P<0.001$. The top three of the subjective symptoms which had a big amount of change were blurred vision ( -1.6 score), photophobia ( -0.6 score), and eye fatigue $(-0.6$ score). However, eye pain and foreign body sensation were not changed significantly, only the latter about non-dry eye subjects before surgery tended to increase (before: 0.4 score, 4 weeks after: 0.5 score, $P=0.323$, the Wilcoxon rank-sum test). Schirmer I test did not change significantly between before surgery and 4 weeks after surgery.

\section{Prevalence and change of diagnostic classification of dry eye before and after cataract surgery}

Table 3 shows the prevalence and the change of diagnostic classification of dry eye before and 4 weeks after cataract surgery. Before cataract surgery, 69.7\% (302 patients) of the total patients were diagnosed with definite or probable dry eye. But, at 4 weeks after cataract surgery, the patients of definite or probable dry eye decreased to $55.7 \%$ (241 patients).

About the change of diagnostic classification, 31.1\% (75 patients) of the total patients diagnosed with definite or probable dry eye at 4 weeks after surgery were classified as having developed dry eye (from non-dry eye to probable or definite dry eye) or worsened dry eye (from probable dry eye to definite dry eye). Also, $31.3 \%$ (41 subjects) of the non-dry eye subjects before surgery changed to having developed dry eye (to definite or probable) at 4 weeks after surgery. On the other hand, $22.4 \%$ of definite dry eye and $38.2 \%$ of probable dry eye before surgery were changed to non-dry eye 4 weeks after surgery.

\section{Type of dry eye before and 4 weeks after surgery}

We analyzed the ratio according to dry eye types before and 4 weeks after surgery. Before surgery, the percentage of unstable tear film dry eye was $57.0 \%$. It was larger than the one of tear-deficient dry eye (36.4\%). At 4 weeks after surgery, the percentage of unstable tear film dry eye was $53.1 \%$. It was larger than the one of tear-deficient dry eye $(28.2 \%)$ too.

\section{Risk factors of dry eye 4 weeks after cataract surgery}

Table 4 shows the risk analysis for dry eye 4 weeks after cataract surgery according to patient demographics and the result of the dry eye test before surgery. Females were more likely to develop dry eye 4 weeks after cataract surgery, and the odds ratio was 3.149 times significantly higher than males $(P<0.001)$. Shorter BUT $(\leq 5 \mathrm{~s})$ had significantly higher risks than normal BUT ( $>5 \mathrm{~s} ; 3.959$ times, $P<0.001)$. Also, patients with fluorescein staining scores had a significantly higher risk than those without $(P<0.001)$. Furthermore, patients with subjective symptoms (eye fatigue, eye discomfort, dryness, and photophobia) also had a significantly

Table 3 The prevalence and the change of diagnostic classification of dry eye before and 4 weeks after cataract surgery

\begin{tabular}{|c|c|c|c|c|c|c|c|}
\hline & & & \multicolumn{5}{|c|}{ Classification of dry eye diagnosis before surgery } \\
\hline & & & \multirow{2}{*}{$\begin{array}{l}\text { Non-dry } \\
\text { eye (\%) }\end{array}$} & \multicolumn{3}{|c|}{ Dry eye patient } & \multirow[t]{2}{*}{ Total (\%) } \\
\hline & & & & Probable (\%) & Definite (\%) & $\begin{array}{l}\text { Probable }+ \\
\text { definite (\%) }\end{array}$ & \\
\hline \multicolumn{3}{|c|}{ The prevalence of dry eye before cataract surgery } & $|3|(30.3)$ & $217(50.1)$ & $85(19.6)$ & $302(69.7)$ & $433(100.0)$ \\
\hline \multicolumn{3}{|c|}{ Number of patients analyzed } & $|3|(\mid 00.0)$ & $217(100.0)$ & $85(100.0)$ & $302(100.0)$ & $433(100.0)$ \\
\hline Classification of dry eye & Non-dry eye & & $90(68.7)$ & $83(38.2)$ & $19(22.4)$ & $102(33.8)$ & $192(44.3)$ \\
\hline diagnosis 4 weeks after & Dry eye patient & Probable & $30(22.9)$ & $100(46.1)$ & $38(44.7)$ & $138(45.7)$ & $168(38.8)$ \\
\hline \multirow[t]{2}{*}{ surgery } & & Definite & II (8.4) & $34(15.7)$ & $28(32.9)$ & $62(20.5)$ & $73(16.9)$ \\
\hline & & Probable + definite & $4 \mid(3 \mid .3)$ & $134(6 \mid .8)$ & $66(77.6)$ & $200(66.2)$ & $24 \mid(55.7)$ \\
\hline
\end{tabular}


Table 4 Risk analysis for dry eye 4 weeks after cataract surgery according to patient demographics and the result of the dry eye test before surgery

\begin{tabular}{|c|c|c|c|c|}
\hline \multirow[t]{2}{*}{ Background factors } & \multirow[t]{2}{*}{ Category } & \multicolumn{3}{|c|}{ Univariate logistic regression analysis } \\
\hline & & Odds ratio & $\begin{array}{l}95 \% \text { confidence } \\
\text { interval }\end{array}$ & $P$-value \\
\hline \multicolumn{5}{|l|}{ Demographics } \\
\hline \multirow[t]{2}{*}{ Sex } & Male & Reference & - & - \\
\hline & Female & 3.149 & $2.122-4.674$ & $<0.00 I^{* *}$ \\
\hline \multirow[t]{4}{*}{ Age (years) } & $<60$ & Reference & - & - \\
\hline & $\geq 60,<70$ & 0.689 & $0.284-1.672$ & 0.410 \\
\hline & $\geq 70,<80$ & 0.718 & $0.304-1.697$ & 0.450 \\
\hline & $\geq 80$ & 0.617 & $0.238-1.596$ & 0.319 \\
\hline \multirow[t]{3}{*}{ Site of incision } & Cornea & Reference & - & - \\
\hline & Sclerocornea & 1.570 & $0.948-2.600$ & 0.080 \\
\hline & Transconjunctival sclerocornea & 1.406 & $0.911-2.17 \mid$ & 0.124 \\
\hline \multirow[t]{3}{*}{ Surgical time (minutes) } & $<10$ & Reference & - & - \\
\hline & $\geq 10,<20$ & 1.214 & $0.77 \mid-1.911$ & 0.402 \\
\hline & $\geq 20$ & 0.830 & $0.236-2.921$ & $0.77 \mid$ \\
\hline \multicolumn{5}{|c|}{ The result of the dry eye test before surgery } \\
\hline Tear breakup time & $>5$ & Reference & - & - \\
\hline (seconds) & $\leq 5$ & 3.959 & $2.585-6.062$ & $<0.001 * *$ \\
\hline $\begin{array}{l}\text { Corneal and } \\
\text { conjunctival }\end{array}$ & Score 0 & Reference & - & - \\
\hline Fluorescein staining & Score I, 2 & 2.980 & $1.893-4.693$ & $<0.001 * *$ \\
\hline Score & $\geq$ Score 3 & 4.822 & $2.784-8.351$ & $<0.00$ I** \\
\hline \multirow[t]{2}{*}{ Schirmer I test $(\mathrm{mm})$} & $\leq 5$ & Reference & - & - \\
\hline & $>5$ & 0.756 & $0.497-1.149$ & 0.190 \\
\hline \multicolumn{5}{|c|}{ Subjective symptom score before surgery } \\
\hline \multirow[t]{2}{*}{ Eye fatigue } & Score 0,1 & Reference & - & - \\
\hline & $\geq$ Score 2 & 2.130 & $1.417-3.202$ & $<0.00 I^{* *}$ \\
\hline \multirow[t]{2}{*}{ Eye pain } & Score 0,1 & Reference & - & - \\
\hline & $\geq$ Score 2 & $3.27 \mid$ & $1.304-8.203$ & $0.012^{*}$ \\
\hline \multirow[t]{2}{*}{ Eye discharge } & Score 0,1 & Reference & - & - \\
\hline & $\geq$ Score 2 & 1.505 & $0.792-2.860$ & 0.212 \\
\hline \multirow[t]{2}{*}{ Foreign body sensation } & Score 0,1 & Reference & - & - \\
\hline & $\geq$ Score 2 & 2.109 & $1.157-3.846$ & $0.015^{*}$ \\
\hline \multirow[t]{2}{*}{ Tearing } & Score 0,1 & Reference & - & - \\
\hline & $\geq$ Score 2 & 0.930 & $0.560-1.546$ & 0.780 \\
\hline \multirow[t]{2}{*}{ Blurred vision } & Score 0,1 & Reference & - & - \\
\hline & $\geq$ Score 2 & 1.129 & $0.758-1.682$ & 0.551 \\
\hline \multirow[t]{2}{*}{ Itchy eye } & Score 0,1 & Reference & - & - \\
\hline & $\geq$ Score 2 & 1.596 & $0.924-2.756$ & 0.094 \\
\hline \multirow[t]{2}{*}{ Heaviness } & Score 0,1 & Reference & - & - \\
\hline & $\geq$ Score 2 & 2.709 & $1.459-5.030$ & 0.002 \\
\hline \multirow[t]{2}{*}{ Red eye } & Score 0,1 & Reference & - & - \\
\hline & $\geq$ Score 2 & 2.249 & $1.020-4.960$ & $0.045^{*}$ \\
\hline \multirow[t]{2}{*}{ Eye discomfort } & Score 0,1 & Reference & - & - \\
\hline & $\geq$ Score 2 & 2.815 & $|.726-4.59|$ & $<0.001 * *$ \\
\hline \multirow[t]{2}{*}{ Dryness } & Score 0,1 & Reference & - & - \\
\hline & $\geq$ Score 2 & 2.885 & $1.609-5.174$ & $<0.00 I^{* *}$ \\
\hline Photophobia & Score 0,1 & Reference & - & - \\
\hline & $\geq$ Score 2 & 2.177 & $1.47 \mid-3.220$ & $<0.00 I^{* *}$ \\
\hline
\end{tabular}

Notes: $* P<0.05, * * P<0.001$, corneal and conjunctival fluorescein staining scores were evaluated in three areas (the temporal bulbar conjunctiva, nasal bulbar conjunctiva, and cornea), scored on a 0 - to 3 -point scale ( 0 : no damage to 3 : damage in the entire area) and then totaled (maximum $=9$ points). Subjective symptom score: score $0=$ never, score $\mathrm{I}=$ rarely, score $2=$ sometimes, and score $3=$ all of the time. 
Table 5 Patient background of prospective randomized study

\begin{tabular}{|c|c|c|c|}
\hline \multirow[t]{2}{*}{ Background factor } & \multicolumn{2}{|c|}{ Randomized group } & \multirow[t]{2}{*}{ Comparison among groups } \\
\hline & DQS (\%) & AT (\%) & \\
\hline Number of patients analyzed & $75(100.0)$ & $79(100.0)$ & - \\
\hline \multicolumn{4}{|l|}{ Sex } \\
\hline Male & $30(40.0)$ & $23(29.1)$ & \multirow[t]{2}{*}{ Fisher's exact test, $P=0.177$} \\
\hline Female & $45(60.0)$ & $56(70.9)$ & \\
\hline \multicolumn{4}{|l|}{ Age (years) } \\
\hline Mean \pm SD & $71.7 \pm 7.4$ & $70.3 \pm 7.1$ & $t$-test, $P=0.227$ \\
\hline \multicolumn{4}{|l|}{ Site of incision } \\
\hline Corneal incision & $25(33.3)$ & $26(32.9)$ & \multirow[t]{3}{*}{ Fisher's exact test, $P=0.899$} \\
\hline Sclerocorneal incision & $23(30.7)$ & $22(27.8)$ & \\
\hline Transconjunctival sclerocorneal incision & $27(36.0)$ & $31(39.2)$ & \\
\hline \multicolumn{4}{|l|}{ Width of incision (mm) (phacoemulsification) } \\
\hline Mean \pm SD & $2.3 I \pm 0.14$ & $2.30 \pm 0.16$ & $t$-test, $P=0.603$ \\
\hline \multicolumn{4}{|l|}{ Anesthetic procedure } \\
\hline With eye drops & $70(93.3)$ & $72(91.1)$ & \multirow[t]{3}{*}{ Fisher's exact test, $P=1.000$} \\
\hline With retrobulbar injection & $0(0.0)$ & $\mathrm{I}(\mathrm{I} .3)$ & \\
\hline With tenon injection & $5(6.7)$ & $6(7.6)$ & \\
\hline \multicolumn{4}{|l|}{ Surgical time (minutes) } \\
\hline Mean \pm SD & $8.6 \pm 3.3$ & $8.2 \pm 3.2$ & $t$-test, $P=0.495$ \\
\hline \multicolumn{4}{|l|}{ Schirmer I test $(\mathrm{mm})$ ( 4 weeks after surgery) } \\
\hline Mean \pm SD & $11.6 \pm 9.6$ & $12.5 \pm 10.9$ & $t$-test, $P=0.592$ \\
\hline
\end{tabular}

Abbreviations: AT, artificial tears; DQS, diquafosol ophthalmic solution; SD, standard deviation.

higher risk than those without $(P<0.001)$. On the other hand, there was no significant difference related to the incision procedure, site of incision, anesthetic procedure, antiseptic procedure, surgical time, Schirmer I test, and a part of subjective symptoms (eye discharge, tearing, blurred vision, and itchy eye).

\section{Prospective randomized study with DQS or AT}

One hundred and seventy-eight qualified patients were randomized (DQS: 85 patients; AT: 93 patients). After randomization, nine patients were dropped out. Before statistical analysis, 15 patients were excluded. The reasons of dropping out were an adverse event (one patient of the AT group, allergic conjunctivitis) and personal reasons (eight patients). The reasons of exclusions were due to the lack of inclusion criteria for the randomized study (12 patients) and the lack of instillation (3 patients). A total of 154 patients (DQS: 75 patients; AT: 79 patients) were analyzed for the prospective randomized study. Table 5 shows the background of 154 patients. There was no significant difference between DQS and AT groups.

Table 6 shows the change of BUT in total patients before and after treatment. In the DQS group, BUT was significantly increased than before $(P=0.015)$. In the AT group, there was no significant change $(P=0.085)$. About the definite dry eye patient before surgery, BUT of the DQS group significantly increased than before treatment $(P=0.018)$, but did not change in the AT group $(P=0.972)$. There was a significant difference between DQS and AT $(P=0.028)$.

Table 7 shows the change of fluorescein staining score in total patients. Both groups showed significant improvement after the treatment $(P<0.001)$. About the definite dry eye patient before surgery, both groups tended to decrease but not significantly.

Table 8 shows the change of total score of 12 subjective symptoms in total patients before surgery. Total subjective symptom score of the AT group significantly decreased $(P<0.001)$. It tended to decrease in the DQS group but not significantly. About the definite dry eye patients before surgery, both groups tended to decrease but not significantly.

\section{Discussion}

In this observational study, we investigated the influence on ocular surface after the prevalence of dry eye post cataract surgery by the dry eye examination and compared the prevalence of dry eye pre- and post-cataract surgery to evaluate the impact of surgery on it. It was confirmed that cataract surgery shortened BUT and increased the fluorescein ocular surface staining score. Moreover, the majority of postoperative dry eye was revealed to be of the unstable tear film type. Based on the Japanese dry eye diagnostic criteria, ${ }^{23}$ the prevalence 
Table 6 Change of tear breakup time (seconds) in prospective randomized study

\begin{tabular}{|c|c|c|c|c|}
\hline & \multicolumn{2}{|l|}{ Examination point } & \multirow[t]{2}{*}{ Amount of change } & \multirow{2}{*}{$\begin{array}{l}\text { Comparison within-group } \\
\text { one-sample } t \text {-test (P-value) }\end{array}$} \\
\hline & $\begin{array}{l}\text { Before treatment } \\
\text { ( } 4 \text { weeks after } \\
\text { surgery) }\end{array}$ & $\begin{array}{l}\text { After treatment } \\
\text { ( } 8 \text { weeks after } \\
\text { surgery) }\end{array}$ & & \\
\hline \multicolumn{5}{|l|}{ Total patients } \\
\hline \multicolumn{5}{|l|}{ DQS } \\
\hline Mean \pm SD & $3.32 \pm 1.62$ & $3.92 \pm 1.87$ & $0.60 \pm 2.11$ & $0.015^{*}$ \\
\hline Median & 3.33 & 3.67 & 0.67 & \\
\hline Number of patients & 75 & 75 & 75 & \\
\hline \multicolumn{5}{|l|}{ AT } \\
\hline Mean \pm SD & $3.13 \pm 1.69$ & $3.48 \pm 1.69$ & $0.35 \pm 1.76$ & 0.085 \\
\hline Median & 3.00 & 3.33 & 0.33 & \\
\hline Number of patients & 79 & 79 & 79 & \\
\hline $\begin{array}{l}\text { Comparison between groups } \\
\text { two-sample } t \text {-test ( } P \text {-value) }\end{array}$ & 0.489 & 0.125 & 0.410 & \\
\hline \multicolumn{5}{|c|}{ The definite dry eye patient before surgery } \\
\hline \multicolumn{5}{|c|}{ DQS } \\
\hline Mean \pm SD & $3.25 \pm 1.27$ & $4.18 \pm 1.82$ & $0.93 \pm 1.61$ & $0.018^{*}$ \\
\hline Median & 3.33 & 4.17 & 1.00 & \\
\hline Number of patients & 20 & 20 & 20 & \\
\hline \multicolumn{5}{|l|}{ AT } \\
\hline Mean \pm SD & $3.00 \pm 1.94$ & $2.99 \pm 1.71$ & $-0.01 \pm 1.88$ & 0.972 \\
\hline Median & 2.67 & 3.00 & 0.00 & \\
\hline Number of patients & 25 & 25 & 25 & \\
\hline $\begin{array}{l}\text { Comparison between groups } \\
\text { two-sample } t \text {-test ( } P \text {-value) }\end{array}$ & 0.622 & $0.028^{*}$ & 0.081 & \\
\hline
\end{tabular}

Note: $* P<0.05$

Abbreviations: AT, artificial tears; DQS, diquafosol ophthalmic solution; SD, standard deviation.

Table 7 Change of corneal and conjunctival fluorescein staining scores in prospective randomized study

\begin{tabular}{|c|c|c|c|c|}
\hline & \multicolumn{2}{|l|}{ Examination point } & \multirow[t]{2}{*}{ Amount of change } & \multirow{2}{*}{$\begin{array}{l}\text { Comparison within-group } \\
\text { one-sample } t \text {-test ( } P \text {-value) }\end{array}$} \\
\hline & $\begin{array}{l}\text { Before treatment } \\
\text { ( } 4 \text { weeks after } \\
\text { surgery) }\end{array}$ & $\begin{array}{l}\text { After treatment } \\
\text { (8 weeks after } \\
\text { surgery) }\end{array}$ & & \\
\hline \multicolumn{5}{|l|}{ Total patients } \\
\hline \multicolumn{5}{|l|}{ DQS } \\
\hline Mean \pm SD & $2.1 \pm 0.9$ & $1.6 \pm 1.2$ & $-0.6 \pm 1.2$ & $<0.00 I^{* *}$ \\
\hline Median & 2.0 & 1.0 & -1.0 & \\
\hline Number of patients & 75 & 75 & 75 & \\
\hline \multicolumn{5}{|l|}{ AT } \\
\hline Mean \pm SD & $2.4 \pm I .1$ & $1.8 \pm 1.3$ & $-0.6 \pm 1.2$ & $<0.00 I^{* *}$ \\
\hline Median & 2.0 & 2.0 & 0.0 & \\
\hline Number of patients & 79 & 78 & 78 & \\
\hline $\begin{array}{l}\text { Comparison between groups } \\
\text { two-sample } t \text {-test ( } P \text {-value) }\end{array}$ & 0.169 & 0.322 & 0.826 & \\
\hline \multicolumn{5}{|c|}{ The definite dry eye patient before surgery } \\
\hline \multicolumn{5}{|c|}{ DQS } \\
\hline Mean \pm SD & $2.9 \pm 0.9$ & $2.3 \pm 1.3$ & $-0.6 \pm 1.3$ & $<0.077$ \\
\hline Median & 3.0 & 2.0 & -0.5 & \\
\hline Number of patients & 20 & 20 & 20 & \\
\hline \multicolumn{5}{|l|}{ AT } \\
\hline Mean \pm SD & $2.8 \pm 1.3$ & $2.5 \pm 1.2$ & $-0.4 \pm 1.2$ & $<0.153$ \\
\hline Median & 2.0 & 2.5 & 0.0 & \\
\hline Number of patients & 25 & 24 & 24 & \\
\hline $\begin{array}{l}\text { Comparison between groups } \\
\text { two-sample } t \text {-test ( } P \text {-value) }\end{array}$ & 0.887 & 0.674 & 0.653 & \\
\hline
\end{tabular}

Notes: $* * P<0.001$, corneal and conjunctival fluorescein staining scores were evaluated in three areas (the temporal bulbar conjunctiva, nasal bulbar conjunctiva, and cornea), scored on a 0- to 3-point scale (0: no damage to 3: damage in the entire area) and then totaled (maximum $=9$ points).

Abbreviations: AT, artificial tears; DQS, diquafosol ophthalmic solution; SD, standard deviation. 
Table 8 Change of total score of 12 subjective symptoms in prospective randomized study

\begin{tabular}{|c|c|c|c|c|}
\hline & \multicolumn{2}{|l|}{ Examination point } & \multirow[t]{2}{*}{ Amount of change } & \multirow{2}{*}{$\begin{array}{l}\text { Comparison within-group } \\
\text { one-sample the Wilcoxon } \\
\text { rank-sum test ( } P \text {-value) }\end{array}$} \\
\hline & $\begin{array}{l}\text { Before treatment } \\
\text { ( } 4 \text { weeks after } \\
\text { surgery) }\end{array}$ & $\begin{array}{l}\text { After treatment } \\
\text { (8 weeks after } \\
\text { surgery) }\end{array}$ & & \\
\hline \multicolumn{5}{|l|}{ Total patients } \\
\hline \multicolumn{5}{|l|}{ DQS } \\
\hline Mean \pm SD & $7.5 \pm 4.4$ & $7.1 \pm 5.5$ & $-0.6 \pm 5.5$ & 0.170 \\
\hline Median & 7.0 & 5.0 & -1.0 & \\
\hline Number of patients & 74 & 73 & 72 & \\
\hline \multicolumn{5}{|l|}{ AT } \\
\hline Mean \pm SD & $7.8 \pm 5.0$ & $6.1 \pm 5.1$ & $-1.7 \pm 4.8$ & $<0.00 I^{* *}$ \\
\hline Median & 6.0 & 5.0 & -1.0 & \\
\hline Number of patients & 79 & 78 & 78 & \\
\hline $\begin{array}{l}\text { Comparison between groups two- } \\
\text { sample the Wilcoxon rank-sum test }\end{array}$ & $P=0.996$ & $P=0.177$ & $P=0.248$ & \\
\hline \multicolumn{5}{|l|}{ The definite dry eye patient before surgery } \\
\hline \multicolumn{5}{|l|}{ DQS } \\
\hline Mean \pm SD & $8.8 \pm 5.4$ & $8.3 \pm 4.3$ & $-0.6 \pm 4.9$ & 0.599 \\
\hline Median & 8.5 & 7.0 & -1.0 & \\
\hline Number of patients & 20 & 19 & 19 & \\
\hline \multicolumn{5}{|l|}{ AT } \\
\hline Mean $\pm S D$ & $8.3 \pm 4.4$ & $8.3 \pm 6.6$ & $0.0 \pm 5.6$ & 0.100 \\
\hline Median & 7.0 & 7.0 & -1.0 & \\
\hline Number of patients & 25 & 25 & 25 & \\
\hline $\begin{array}{l}\text { Comparison between groups two- } \\
\text { sample the Wilcoxon rank-sum test }\end{array}$ & $P=0.827$ & $P=0.584$ & $P=0.867$ & \\
\hline
\end{tabular}

Notes: ${ }^{*} * \mathrm{P}<0.00 \mathrm{I}$, subjective symptom score; score $0=$ never, score $\mathrm{I}=$ rarely, score $2=$ sometimes, score $3=$ all of the time.

Abbreviations: AT, artificial tears; DQS, diquafosol ophthalmic solution; SD, standard deviation.

of post cataract surgery dry eye was $55.7 \%$, and the incidence of dry eye from non-dry eye subjects was $31.3 \%$ postoperatively. In addition, in a consecutive prospective multicenter randomized study, we confirmed that the dry eye medication is effective in preventing these signs and symptoms. It is worthwhile to discuss the results obtained relating these data to the pathogenesis of perioperative dry eye syndrome.

The prevalence of dry eye 4 weeks after cataract surgery decreased than that before surgery as expected. When we pay attention to the individual data of dry eye examination, we can recognize that BUT and fluorescein ocular surface staining score turned worse, but only the total subjective symptom score was largely improved. Naturally, blurred vision and photophobia which may be caused by cataract were improved with a big amount of change. In addition to that, the postoperative topical application of steroids, antibacterial drugs, and NSAIDs for 4 weeks may contribute to the improvement of dry eye. As NSAIDs and steroids, respectively, have an anesthesia ${ }^{36}$ and anti-inflammatory effect, a variety of dry eye symptoms might be ameliorated. Therefore, the treatment with them for 4 weeks after cataract surgery might reduce the dry eye prevalence, comparing to the first rate after the operation. If we would like to find out the influence of cataract surgery for dry eye prevalence and incidence, the subjects should be examined after surgery at an earlier time, for example, several days later or 1 week later.

We further analyzed the risk factors leading to postoperative dry eye and found that female patients and patients with shorter BUT, with greater ocular surface staining score, or having the dry eye-related subjective symptom such as eye fatigue, eye pain, dull sensation, eye discomfort, dryness, and photophobia, all preoperatively are at risk to encounter postoperative dry eye. These risk factors are in line with features reported in the epidemiological study of dry eye in the elderly Japanese population. ${ }^{37}$ Hence, patients with any of these factors should be expected to encounter postoperative dry eye and its countermeasures must be considered.

In this observational study, we found that cataract surgery with IOL implantation shortened BUT. In fact, the eyes without dry eye before surgery resulted in more significant shortening of BUT. It suggests that tear film instability is greatly involved in the pathogenesis of dry eye after cataract surgery. Risk factors of perioperative damage were reported as light from the operative microscope, incision wound, aging, forceful opening of the eye lids, topical anesthetics, cleansing of the conjunctival sac and lids with povidone iodine, topical NSAIDs, and preservatives in eye drops. ${ }^{5-14}$ These risk factors damage the ocular surface epithelium or the tear film or both 
and become causes of dry eye via the vicious cycle between unstable tear film and damaged epithelium. Damaged epithelium is thought to involve squamous metaplasia with reduction of goblet cells or lack of microvilli. ${ }^{16}$ Shortening of BUT and an increase in staining score that we confirmed in this study are therefore thoroughly understandable. In this study, we revealed notable knowledge in perioperative medical care that in postoperative dry eye patients without dry eye before surgery, even if in non-dry eye subjects, through the surgery, the tear film stability was remarkably altered resulting in short BUT. It is indeed interesting that intraoperative risk factors increase the incidence of acute, iatrogenic, and specific dry eye-related syndrome.

Diquafosol is a dinucleotide derivative and exhibits purinoceptor $\mathrm{P} 2 \mathrm{Y}_{2}$ receptor agonist activity. ${ }^{38} \mathrm{P} 2 \mathrm{Y}_{2}$ receptor agonists, such as diquafosol and uridine $5^{\prime}$-triphosphate, have been reported to enhance the secretion of water and secretory mucin from conjunctival tissue and the expression of membrane-associated mucin..$^{25-27,30,39}$ Mucin is widely distributed throughout mucous tissues and it works to moisten mucous membranes and prevents them from damage. The lack of mucin on ocular surface reduced wettability to induce unstable tear film, and short BUT type dry eye was often seen clinically. ${ }^{40-42}$ These findings indicate that mucin, together with aqueous tears, works to contribute to tear film stability. We revealed that in this study, the majority of the dry eye type was short BUT type (unstable tear film dry eye) rather than tear-deficient dry eye before and after cataract surgery.

We confirmed that in comparison to AT, DQS was effective in the improvement of tear film instability. General dry eye syndrome induced by various risk factors is thought to be a chronic disorder. ${ }^{3,23,24}$ Conversely, the perioperative occurrence of dry eye due to specific risk factors ${ }^{5-14}$ is similar to this, but is a non-physiological iatrogenic and acute disorder. With this disorder, the risk factors damage the epithelium, reduce goblet cell density, and shorten BUT. ${ }^{16,19,20}$ As stated earlier, there is a profound rationale to provide DQS, which enhances water and mucin secretion, to eyes of this pathological state. In addition, the following interesting facts were discovered as the study evaluated eyes before surgery and all the way through postoperatively. The treatment with DQS showed a more remarkable effect on definite dry eye before surgery. Until recently, ophthalmic viscosurgical devices and balanced salt solutions have been used to address perioperative dry eye. By using DQS, we can cause a paradigm shift from simply lubricating and hydrating the ocular surface with products such as AT to more reasonable methods. ${ }^{19-20}$
Although some reports have shown that studies reporting the incidence of dry eye after cataract surgery with IOL implantation are scarce, ${ }^{18}$ there has been no prospective multicenter study done on this subject. In the present study, we found the prevalence of postoperative dry eye to be $55.7 \%$ accordingly to the Japanese criteria of dry eye, ${ }^{23}$ and the incidence of dry eye was $\sim 31.3 \%$ at 4 weeks after cataract surgery. These numbers are meaningful in that they suggest that a substantial number of eyes develop dry eye following cataract surgery with IOL implantation, strongly indicating an urgent need for appropriate clinical management of this disorder due to its acute and iatrogenic nature. This is because such dry eye leads to a unique pathological condition of ocular discomfort as well as disturbs the quality of vision, and it is a disorder to be noted that influences the outcome of cataract surgery with IOL implantation. Together with the evaluation of pre- and postoperative condition of dry eye, a sufficient protocol to control the disorder needs to be determined. In late years, there have been some reports that examined an effect of DQS for dry eye after cataract surgery. The application of DQS improves signs including higher order aberrations and symptoms in dry eye patients after cataract surgery. ${ }^{21,22,43-45}$ Higher-order aberrations were not investigated in this study, but they may be improved because tear film stability was improved to prolong BUT in the diquafosol treatment group. Hence, it became apparent that DQS, a new type of drug that enhances secretion of mucin and water, should be considered one of the treatment options to tackle perioperative dry eye.

This study has some limitations. In this study, we did not standardize the surgery procedure. Results may vary according to the site of incision and type of anesthesia. To know rationality to use a new drug, to know whether the drug has any other harmful effects, and to know whether it is cost-effective, further study may be undertaken. On the other hand, we examined an effect to postoperative dry eye only about DQS and AT. The eye drops which we can use for dry eye treatment exist as well as AT and DQS. We should consider conducting the further comparative studies with other lubricating eye drops.

\section{Conclusion}

Cataract surgery has a harmful effect on tear stability and ocular surface. Therefore, perioperative examination and the treatment of dry eye may be useful for the patient to set their satisfaction for cataract surgery higher. Our study suggests that in the dry eye medications after cataract surgery, 
DQS is better alternative to AT and DQS is a promising candidate for it.

\section{Acknowledgments}

The authors thank Dry Eye After Cataract Surgery Investigational Study (DASIS) Group: Yasushi Inoue, MD (Inoue Eye Clinic, Okayama, Japan), Yuya Nomura, MD (Fujita Eye Clinic, Tokushima, Japan), Kohei Ishikawa, MD (Ishikawa Eye Clinic, Shizuoka, Japan), Yuji Sakka, MD (Sakka Eye Clinic, Fukuoka, Japan), Teruyuki Miyoshi, MD, PhD (Miyoshi Eye Center, Hiroshima, Japan), Toshitaka Itabashi, MD, PhD (Itabashi Eye clinic, Miyagi, Japan), Kiichiro Kusaba, MD (Tane Memorial Eye Hospital, Osaka, Japan), Hitoshi Okabe, MD (Heisei Eye Hospital, Miyagi, Japan), Ken Hayashi, MD, PhD (Hayashi Eye Hospital, Fukuoka, Japan), Shinichi Itoh, MD (Itoh Eye Clinic, Aomori, Japan), and Hiromitsu Hitani, MD, PhD (Hitani Eye Clinic, Hiroshima, Japan) for plan drafting and data collecting. They also thank Yoshiaki Yamada (Department of Medical affairs, Santen Pharmaceutical Co., Ltd., Osaka, Japan).

This study was performed under a contract of a collaborative joint clinical research between DASIS group and Santen Pharmaceutical Co., Ltd.

This study was funded by Santen Pharmaceutical Co., Ltd., Osaka. The funding organization participated in the design of the study, interpretation of the data, preparation, review, and approval of the manuscript.

\section{Disclosure}

KM received grants, personal fees and non-financial supports from Santen Pharmaceutical Co., Ltd. during the conduct of this study. NY received personal fees and non-financial supports from Santen Pharmaceutical Co., Ltd during the conduct of this study. The authors report no other conflicts of interest in this work.

\section{References}

1. Altmann GE. Wavefront-customized intraocular lenses. Curr Opin Ophthalmol. 2004;15(4):358-364.

2. Troutman RC, Buzard KA. Corneal astigmatism: etiology, prevention and management. J Refract Surg. 1992;8(5):410.

3. International Dry Eye WorkShop. 2007 Report of the international dry eye workshop (DEWS). Ocular Surf. 2007;5(2):65-202.

4. Garcia-Catalan MR, Jerez-Olivera E, Benitez-Del-Castillo-Sanchez JM. Dry eye and quality of life. Arch Soc Esp Oftalmol. 2009;84(9):451-458. Spanish.

5. Nakamori K, Odawara M, Nakajima T, Mizutani T, Tsubota K. Blinking is controlled primarily by ocular surface conditions. Am J Ophthalmol. 1997;124(1):24-30.

6. Mathers WD, Lane JA, Zimmerman MB. Tear film changes associated with normal aging. Cornea. 1996;15(3):229-234.
7. Patel S, Farrell JC. Age-related changes in precorneal tear film stability. Optom Vis Sci. 1989;66(3):175-178.

8. Paschides CA, Stefaniotou M, Papageorgiou J, Skourtis P, Psilas K. Ocular surface and environmental changes. Acta Ophthalmol Scand. 1998;76(1):74-77.

9. Cho YK, Kim MS. Dry eye after cataract surgery and associated intraoperative risk factors. Korean J Ophthalmol. 2009;23(2):65-73.

10. Pisella PJ, Pouliquen P, Baudouin C. Prevalence of ocular symptoms and signs with preserved and preservative free glaucoma medication. Br J Ophthalmol. 2002;86(4):418-423.

11. Congdon NG, Schein OD, Kulajta P, Lubomski LH, Gilbert D, Katz J. Corneal complications associated with topical ophthalmic use of nonsteroidal antiinflammatory drugs. J Cataract Refract Surg. 2001;27(4):622-631.

12. Pharmakakis NM, Katsimpris JM, Melachrinou MP, Koliopoulos JX. Corneal complications following abuse of topical anesthetics. Eur J Ophthalmol. 2002;12(5):373-378.

13. Chen HT, Chen KH, Hsu WM. Toxic keratopathy associated with abuse of low-dose anesthetic; a case report. Cornea. 2004;23(5):527-529.

14. Yanai R, Yamada N, Ueda K, et al. Evaluation of povidone-iodine as a disinfectant solution for contact lenses: antimicrobial activity and cytotoxicity for corneal epithelial cells. Contact Lens Anterior Eye. 2006; 29(2):85-91.

15. Li XM, Hu L, Hu J, Wang W. Investigation of dry eye disease and analysis of the pathogenic factors in patients after cataract surgery. Cornea. 2007;26(9 Suppl 1):S16-S20.

16. Oh T, Jung Y, Chang D, Kim J, Kim H. Changes in the tear film and ocular surface after cataract surgery. Jpn J Ophthalmol. 2012;56(2): $113-118$.

17. Hwang HB, Kim HS. Phototoxic effects of an operating microscope on the ocular surface and tear film. Cornea. 2014;33(1):82-90.

18. Kasetsuwan N, Satitpitakul V, Changul T, Jariyakosol S. Incidence and pattern of dry eye after cataract surgery. PLoS One. 2013;8(11): e78657.

19. Yao K, Bao Y, Ye J, et al. Efficacy of $1 \%$ carboxymethylcellulose sodium for treating dry eye after phacoemulsification: results from a multicenter, open-label, randomized, controlled study. $B M C$ Ophthalmol. 2015;15:28.

20. Jee D, Park M, Lee HJ, Kim MS, Kim EC. Comparison of treatment with preservative-free versus preserved sodium hyaluronate $0.1 \%$ and fluorometholone $0.1 \%$ eyedrops after cataract surgery in patients with preexisting dry-eye syndrome. J Cataract Refract Surg. 2015;41(4):756-763.

21. Park DH, Chung JK, Seo DR, Lee SJ. Clinical effects and safety of $3 \%$ diquafosol ophthalmic solution for patients with dry eye after cataract surgery: a randomized controlled trial. Am J Ophthalmol. 2016; 163:122-131.e2.

22. Takeshita T. [Effect of diquafosol sodium ophthalmic solution for dry eye after cataract surgery]. Rinsho Ganka. 2013;67(3):327-330. Japanese.

23. Shimazaki J. Dry Eye Research Group in Japan. [Definition and diagnosis of dry eye 2006]. Atarashii Ganka. 2007;24(2):181-184. Japanese.

24. Management and Therapy Subcommittee. Management and therapy of dry eye disease: report of the Management and Therapy Subcommittee of the International Dry Eye WorkShop (2007). Ocular Surf. 2007;5(2):163-178.

25. Jumblatt JE, Jumblatt MM. Regulation of ocular mucin secretion by $\mathrm{P}_{2} \mathrm{Y}_{2}$ nucleotide receptors in rabbit and human conjunctiva. Exp Eye Res. 1998;67(3):341-346.

26. Hosoya KI, Ueda H, Kim KJ, Lee VHL. Nucleotide stimulation of $\mathrm{Cl}^{-}$secretion in the pigmented rabbit conjunctiva. $J$ Pharmacol Exp Ther. 1999;291(1):53-59.

27. Li Y, Kuang K, Yerxa B, Wen Q, Rosskothen H, Fischbarg J. Rabbit conjunctival epithelium transports fluid, and $\mathrm{P} 2 \mathrm{Y}_{2}$ receptor agonists stimulate $\mathrm{Cl}^{-}$and fluid secretion. Am J Physiol Cell Physiol. 2001;281(2): C595-C602. 
28. Murakami T, Fujihara T, Horibe Y, Nakamura M. Diquafosol elicits increases in net $\mathrm{Cl}^{-}$transport through $\mathrm{P} 2 \mathrm{Y}_{2}$ receptor stimulation in rabbit conjunctiva. Ophthalmic Res. 2004;36(2):89-93.

29. Fujihara T, Murakami T, Nagano T, Nakamura M, Nakata K. INS365 suppresses loss of corneal epithelial integrity by secretion of mucin-like glycoprotein in a rabbit short-term dry eye model. J Ocul Pharmacol Ther. 2002;18(4):363-370.

30. Shichijo Y, Nakamura M. Stimulatory effect of diquafosol tetrasodium on the expression of membrane-binding mucin genes in cultured human corneal epithelial cells. Atarashii Ganka. 2011;28(3):425-429. Japanese.

31. Fujihara T, Murakami T, Fujita H, Nakamura M, Nakata K. Improvement of corneal barrier function by the $\mathrm{P}_{2} \mathrm{Y}_{2}$ agonist INS365 in a rat dry eye model. Invest Ophthalmol Vis Sci. 2001;42(1):96-100.

32. Tauber J, Davitt WF, Bokosky JE, et al. Double-masked, placebocontrolled safety and efficacy trial of diquafosol tetrasodium (INS365) ophthalmic solution for the treatment of dry eye. Cornea. 2004; 23(8):784-792.

33. Matsumoto Y, Ohashi Y, Watanabe H, Tsubota K; Diquafosol Ophthalmic Solution Phase 2 Study Group. Efficacy and safety of diquafosol ophthalmic solution in patients with dry eye syndrome: a Japanese Phase 2 clinical trial. Ophthalmology. 2012;119(10):1954-1960.

34. Takamura E, Tsubota K, Watanabe H, Ohashi Y; Diquafosol Ophthalmic Solution Phase 3 Study Group. A randomised, double-masked comparison study of diquafosol versus sodium hyaluronate ophthalmic solutions in dry eye patients. Br J Ophthalmol. 2012;96(10):1310-1315.

35. Toda I, Fujishima H, Tsubota K. Ocular fatigue is the major symptom of dry eye. Acta Ophthalmol (Copenh). 1993;71(3):347-352.
36. Zaidman GW, Amsur K. Diclofenac and its effect on corneal sensation. Arch Ophthalmol. 1995;113(3):262.

37. Uchino M, Dogru M, Yagi Y, et al. The features of dry eye disease in a Japanese elderly population. Optom Vis Sci. 2006;83(11):797-802.

38. Nichols KK, Yerxa B, Kellerman DJ. Diquafosol tetrasodium: a novel dry eye therapy. Expert Opin Invest Drugs. 2004;13(1):47-54.

39. Cowlen MS, Zhang VZ, Warnock L, Moyer CF, Peterson WM, Yerxa BR. Localization of ocular $\mathrm{P} 2 \mathrm{Y}_{2}$ receptor gene expression by in situ hybridization. Exp Eye Res. 2003;77(1):77-84.

40. Toda I, Shimazaki J, Tsubota K. Dry eye with only decreased tear break-up time is sometimes associated with allergic conjunctivitis. Ophthalmology. 1995;102(2):302-309.

41. Danjo Y, Watanabe H, Tisdale AS, et al. Alteration of mucin in human conjunctival epithelia in dry eye. Invest Ophthalmol Vis Sci. 1998; 39(13):2602-2609.

42. Argüeso P, Balaram M, Spurr-Michaud S, Keutmann HT, Dana MR, Gipson IK. Decreased levels of the goblet cell mucin MUC5AC in tear of patients with Sjögren syndrome. Invest Ophthalmol Vis Sci. 2002; 43(4):1004-1011.

43. Miyake G, Ota I, Miyake K, Zako M, Iwaki M. Effects of topical diquafosol pretreatment on intraoperative corneal wetting. $J$ Cataract Refract Surg. 2014;40(10):1682-1688.

44. Baek J, Doh SH, Chung SK. The effect of topical diquafosol tetrasodium 3\% on dry eye after cataract surgery. Curr Eye Res. 2016;41(10): $1281-1285$.

45. Lee JH, Song IS, Kim KL, Yoon SY. Effectiveness and optical quality of topical $3.0 \%$ diquafosol versus $0.05 \%$ cyclosporine a in dry eye patients following cataract surgery. J Ophthalmol. 2016;2016:8150757.
Clinical Ophthalmology

\section{Publish your work in this journal}

Clinical Ophthalmology is an international, peer-reviewed journal covering all subspecialties within ophthalmology. Key topics include: Optometry; Visual science; Pharmacology and drug therapy in eye diseases; Basic Sciences; Primary and Secondary eye care; Patient Safety and Quality of Care Improvements. This journal is indexed on Submit your manuscript here: http://www.dovepress.com/clinical-ophthalmology-journal

\section{Dovepress}

PubMed Central and CAS, and is the official journal of The Society of Clinical Ophthalmology (SCO). The manuscript management system is completely online and includes a very quick and fair peer-review system, which is all easy to use. Visit http://www.dovepress.com/ testimonials.php to read real quotes from published authors. 